\title{
Fit to Context Matters - Selecting and Using Information Systems Development Methods to Develop Business in Digitalization Contexts
}

\author{
Dahlberg, Tomi \\ Turku School of Economics, \\ University of Turku \\ tomi.dahlberg@utu.fi
}

\author{
Lagstedt, Altti \\ Haaga-Helia University of Applied Sciences \\ Turku School of Economics, University of Turku \\ altti.lagstedt@haaga-helia.fi
}

\begin{abstract}
We ponder the relations of software, information systems (IS) and business development methods in the development of digital businesses and in the digitalization of extant businesses. We present our published IS development method (ISDM) framework and its development. The framework is used as the background to reason the relations between the three development layers of digitalization: software, IS and business. We then propose six highly potential areas of future research. In addition, we answer to two research questions also paving the way to future research: is the matching of IS and business development context a reasonable proposition, and is the finding of extant literature true, according to which ISDMs are used limitedly in IS development work. We organized two workshops with $21(14+7)$ participants to answer these questions. We detected yes and mixed answers. We contribute to research with the empirical findings and the proposed research areas.
\end{abstract}

\section{Introduction and background}

We have investigated for some years, what kind of information systems development methods (ISDM) should be selected for use in information systems development (ISD) projects conducted in business development contexts. The purpose of selecting an appropriate ISDM is to increase the probability of a project's success both in terms of the so-called golden triangle project performance metrics (time, money, agreed deliverables, see e.g. [38]) and in terms of value delivered to business from the use of the developed, implemented, rolled out and maintained information system (IS) (e.g. [39]). For obvious reasons, both practitioners (e.g. [40]) and academics have discovered lots of other significant factors that influence the success (e.g. [15, 29]) or failure (e.g. [36]) of ISD projects. The present article, however, focuses only on ISDM selections in business development contexts.
Our interest into ISDM selection started from lengthy discussions around a totally failed ISD project. The project had been a high-profile business critical project in a large global technology industry enterprise with $20000+$ employees, 7 manufacturing sites and $100+$ local offices on all continents. Dozens of business professional from diverse business units and various organizational levels had contributed to the functional specification of the IS. The project team knew well the applied plan-driven (waterfall-type) ISD and project management methods, had long experience about the methods, and had executed successfully several comparable ISD projects. Relevant business managers, including a couple of senior executives from the company's steering committee, were actively involved and provided strong support to the project. Thus, all typical ISD project success factors were present. We collected extensive empirical data about the project by interviewing dozens of people face-toface or in peer groups and by reading voluminous and varied project documents - and we still did not understand what went wrong. How is it possible to have all necessary capabilities and competencies, a solid functional specification and sound project plan, execute everything right by the book, and fail?

The advocates of change-driven (agile) ISDMs perhaps see the reason in the use of plan-driven methods. We considered also that alternative. Still, in our opinion, change-driven methods might have helped to detect the failure reasons earlier but would not alone have been enough to execute the project successfully. Moreover, it has been and still is possible to succeed with plan-driven ISDMs as market reports disclose (e.g. [40]). Then, during a discussion, one of us asked the critical question, did the ISD and project management methods fit to the nature of business development and match with the development methods that were used to develop business process execution. Answering no to that question did not only help us to propose a solution to our challenge but also explained, why the IS that was developed in time within budget 
and delivered all specified functionalities was never taken into use (see [16, 18, 19] for more details).

That question also started a multi-year, still ongoing phenomenon-based research [30] journey, where we adhered strongly to the abductive theorizing logic (e.g. [45]) during the early phases of our research. We explain abductive theorizing logic as follows: At the start of our research journey, we had already coined the idea to investigate the matching of ISDMs' and business development (methods') characteristics in ISDM selection decision-making. We expected that our idea would offer an interesting new venue for research. Another related idea was that IS development is actually an amalgamated part of business development, and should be treated as such, in digital business development and business digitation projects. We were, however, unable to know (in advance) what to expect from the research, especially from the case and expert interview data we collected, since our approach was novel to ISDM selection research and since we did not know how much support prior research would provide to our research. Therefore, we did not test theory-based, deductively reasoned propositions or hypotheses. On the other hand, our approach was not either inductive, since we already had good understanding about extant literature (e.g. [7]) and since we had good knowledge about the issue due to our former and/or current professional positions in industrial IS development and IS management, in systems engineering standardization, and in academic ISD and ISDM research and education.

In abductive reasoning, data analysis proceeds simultaneously with data collection. Analysis results emerge from the loop of going backwards and forwards between existing theoretical insights and emerging empirical findings. After the invention of our research ideas about the match between ISDM and business (process) development methods, we revisited the above discussed ISD failure case together with another totally failed ISD project where the changedriven Scrum ISDM had been used. Although the specific project failure reasons differed, both ISD projects had the same fundamental failure factor; the selected ISDM did not fit to the needs of business development context (for more details see [16]).

At the same time, we conducted a systematic literature review from 1950s until now about ISDM selection models and selection criteria between plandriven and change-driven ISDMs. We found 42 academic works from more than 1000 candidates that had addressed this issue. The ISDM selection models and selection criteria of the 42 publications are summarized in [32]. We also discovered that the idea to match the characteristics of ISDM and business (process) development methods was largely novel to
ISDM selection research. Our idea could still be used to build on the findings of prior research and to augment them. Finally, we reviewed organization research and business process development literature in order to learn, how organizations develop their business (processes), and especially how they react to the changes and variations in their business development contexts.

Finally, we combined the insights of our ideas, the findings of the two ISD failure cases and the two literature reviews. We crafted an interview protocol and an interview instrument with open-ended semistructured interview questions for additional data collection. We recruited 31 experienced ISDM experts from the National (=Finnish) Information Systems Measurements Association (FiSMA) and the national Association for Information Systems Developers (SYTYKE). FiSMA is the national Finnish standardization authority for international systems engineering standards (=ISO/IEC, JTC1, SC7). We also used snowballing to recruit some additional interviewees. All interviewees worked on the borderline of IS user organizations and ISD service provider companies (software houses). During the interviews, we had a rough idea about what gradually evolved into our framework for ISDM selection. We labeled it as "contingency theory motivated framework for the selection of information system development methods", and validated the framework with the interview data and the findings of the systematic literature review [32]. The model will be illustrated in the next section of this article.

During the recent months we have planned new research efforts to develop further our ISDM selection framework and to introduce ISDM selection tools and recommendations. We plan to do so partly with the support of additional exploratory studies that dig deeper into the messy real life of IS and business development work and ISDM selection decisionmaking within digitalization development contexts.

Our article has two objectives motivated by the current status of our research journey. Firstly, the systematic literature review revealed that ISDM selection research had been active during the 1990s and early 2000s. Although there are some recent publications, new models and ideas have been few after the seminal work of Boehm and Turner in 2004 [7]. According to our interview data, the interviewed ISDM experts perceived the extant literature's recommendations for ISDM selection and hence also ISDM selection models outdated [17]. In addition, such terms as IS development, systems development and systems engineering were typically used in extant literature, especially to describe plan-driven ISD. Change-driven ISDMs address the same issue by using 
the term software development. The content of software development is narrower than ISD, of which software development is a part. It seems that in change-driven development, with a narrow software focus and with the distinguishing of software developers from business professionals it appears possible to exclude business development context from software development. Business development context could then be allocated to business professionals, e.g. to "product owners". We conclude that the roles and interactions of software, IS and digital business development need renewed attention.

The birth and proliferation of digital and digitalized processes, software-based and data-driven digital businesses, and the digitalization of extant businesses have changed the landscape of ISD and ISDMs from what it was 15-20 years ago. Developed applications and ISs are now more often related directly to business execution, or even are the business [8]. ISD cosourcing between IS user and service provider organizations and the delivery of software as a service from clouds and "Appstore" are some of the other factors that have increased the variety of applications/ISs and their lifecycles. From this background, the first purpose of our article is to identity relevant research areas for (our) future research on ISDM selection by contemplating the impacts of issues discussed in the two previous paragraphs. In addition to our own research, we offer these research areas as our scientific contributions to other researchers.

Secondly, the literature review and the analysis of interview data produced two findings that surprised us. Prior studies have reported that most ISD projects are executed without the (earnest) use of any ISDM (e.g. [21, 22, 26, 27, 35]). Several reasons may explain this phenomenon. Selected methods may not suit to the IS development task or context. IS developers could be unfamiliar with the selected method or lack experience about the use of the method, as reported by [7, 13, 22, 44]. In these situations, IS developers could camouflage ISDM usage and report what is officially expected from them [2] although the method is not used properly (or at all). Consequently, reliable data about the ISD project practice and ISD progress is unavailable. In the worst case, an ISDM could be blamed for an ISD project failure, although the ISDM was never used. Prior to fixing these challenges any ISDM selection model and ISDM selection recommendations are useless. A few interviewees mentioned this amethodical behavior whereas the majority did not. On the other hand, some interviewees explained that plan-driven ISDM and project management method-based progress reporting practices are used in change-driven ISDM projects.
The biggest surprise to us was that our idea of seeking match between the characteristics of ISDMs and business (process) development contexts was missing almost entirely from extant ISDM selection research. In our opinion, digital businesses and the digitization of existing businesses have increased the importance of this issue. We wanted to understand better the status of the two issues that surprised us prior to any new research efforts. We organized one workshop with the experts of FiSMA and another workshop with the experts of the national chapter of IPMA. The second objective of the present article is to find answers to the following two research questions:

RQ1: How do systems engineering and project management experts perceive the following claim: IS development methods used in ISD projects should fit to the characteristics of business development context.

RQ2: According to extant literature IS development methods are rarely used in earnest in ISD projects. Is this kind of behavior true according to the perceptions of systems engineering and project management experts, and if so or not so for what reasons?

In the next section, we review related research followed by methods and findings sections. We end the article with a discussion and conclusions section.

\section{Related research}

The classification of ISDMs into plan-driven and change-driven methods is done on the basis of ISD control [34]. There are also other classifications, for example by the size of ISD in person-years. We used the classification based on ISD control due to the conceptual clarity of the classification. In addition to that practitioners commonly use plan-driven (waterfall) and change-driven (agile) ISDMs terms, which also describe the professional ISD work. The history of plan-driven and change-driven ISDMs starts from 1950s [6]. In addition to pure plan-driven and changedriven methods, there are hybrid methods and/or it is possible to change from one type of ISDM to another between two consecutive ISD projects. With ISDM selection we thus mean an ISD project specific choice between a plan-driven or a change-driven ISDM.

\subsection{Software, information systems and business development in digitalization contexts}

In the beginning of our research journey, digitalization was not as all-penetrating as it is now. Yet, the market research enterprise Gartner Inc. reported already in 2012 that $80 \%$ of IT investments are allocated outside of so-called traditional IT [46]. Consider the millions of applications downloadable 
from Appstore, numerous ISs available as cloud services with pay as you go charging, the number of Internet sites and stores, embedded IS in devices, digital platforms and portals, applications that process IoT data, applications with artificial intelligence and other algorithms that crunch data, and other software and data-enabled innovations we have seen during the recent years. We are probably not the only ones, who perceive that the development of digital business and the digitalization of existing business, digitalization for short, appears to dominate current ISD work. Also, the business criticality of ISD has increased. In addition to co-sourcing several enterprises have recruited IS developers to develop solutions that offer competitive advantage [3] or lower transaction costs [11]. For these reasons we consider digitalization contexts highly relevant for future ISDM selection research.

It seems evident that no ISDM suits to all ISD projects given the plethora of ISs. They range from applications developed for a single event, such as fewday fairs or a concert, through devise-specific embedded IoT and automation applications to large ERP systems used for decades. Extant research has verified this conclusion time after time [9, 16]. Although both plan-driven and change-driven ISDMs have been used parallelly since 1950s and although both types are needed, it seems that one prevailing ISD paradigm receives almost all attention at a time [41]. A paradigm shift has happened during the last two decades. Plan-driven ISD approach and plan-driven ISDMs were dominant during the 1970s, 1980s and 1990s. Since the late 2000s and early 2010s, changedriven (agile) ISD approach and ISDMs have received the majority of attention. Currently, the most purist advocates of change-driven ISD work and ISDMs are even seen to behave "cult-like"[33]. For example, a couple of the 31 ISD and ISDM experts we interviewed accepted only the use of change-driven ISDMs. Although change-driven ISDMs have been detected to be able to solve some problems of plandriven ISDMs - and vice versa - change-driven ISDMs have been detected to have new problems and limitations of their own [5, 23, 24, 43].

Since there is no silver bullet ISDM and since there are numerous alternatives both among plan-driven and change-driven methods, it is important to know how to select an ISDM for an ISD project. Still, in our opinion, the first decision is to make the selection between plan-driven and change-driven ISDMs. Some of the extant literature's 42 publications present ISDM selection models or frameworks $[1,7,10,25]$, whereas the majority suggests selection criteria without a model or a framework. A summary of those recommendations is available in [17]. The ISDM selection models and frameworks of prior research need updating to digitalization contexts [32]. Prior models reflect the dominance of the plan-driven approach era and the arguments behind the models have been perceived to be outdated [17]. According to our studies, the major and at the same time the most common limitations are focus on technical and other project specific factors and the exclusion of business context characteristics.

Figure 1 illustrates our contingency theory motivated framework for the selection of ISDMs. Its name describes the knowledge bases we used in the crafting of the framework. We applied the ideas of contingency theory (e.g. [42]), which descibes four alternative approaches used by organizations to respond to the uncertainties created by the changes in their business enviroment. Each alternative approach initiates different type of organizational and business development. We added insights from business opportunity and business process researchers, who had proposed comparable alternative approaches to business (process) development unncertainties [32]. The detailed business (process) development characteristics are excluded from the illustration of the framework.

\begin{tabular}{|l|l|l|}
\hline $\begin{array}{l}\text { High business execution } \\
\text { certainty (and high } \\
\text { certainty on how ISDM } \\
\text { supports business } \\
\text { development) }\end{array}$ & $\begin{array}{l}\text { Leans on } \\
\text { change-driven }\end{array}$ & $\begin{array}{l}\text { Leans on plan-driven } \\
\text { Plan-driven ISDMs (and BPDMs) } \\
\text { should be selected and used }\end{array}$ \\
\hline $\begin{array}{l}\text { Low business execution } \\
\text { certainty (and low } \\
\text { certainty on how ISDM } \\
\text { supports business } \\
\text { development) }\end{array}$ & $\begin{array}{l}\text { Change-driven ISDMs (and BPDMs) } \\
\text { should be selected and used }\end{array}$ & $\begin{array}{l}\text { Leans on } \\
\text { change-driven }\end{array}$ \\
\hline & $\begin{array}{l}\text { Low business development outcomes } \\
\text { certainty (and low certainty on how } \\
\text { ISDM supports outcomes achievement) }\end{array}$ & $\begin{array}{l}\text { High business development outcomes } \\
\text { certainty (and high certainty on how } \\
\text { ISDM supports outcomes achievement) }\end{array}$ \\
\cline { 2 - 3 }
\end{tabular}

Figure 1. The contingency theory motivated ISDM selection framework

We then described differences in the key characteristics of plan-driven and change-driven ISDMs and mapped them to the four alternative business development approaches so that the characteristics of business deelopment and IS development matched. The vertical axis of the framework (Figure 1) describes the level of certainty related to the stability and define-ability of business execution when IS and business development is planned and conducted. The horizontal axis captures the certainty related to predictability and define-ability of business outcomes as the result of planned and conducted IS and business development. The lower left-hand side quadrant describes development contexts, where both the execution and the outcomes of development have significant encertainties. The recommendation is to select a change-driven ISDM. Similarly, the upper right-hand side quadrant describes development contexts, where high certainty 
characterises both. The redommendation is to select a plan-driven ISDM

One perspective to ponder the relations between software, IS and business (process) development in digitalization contexts is to consider them as the three layers or facets of IT-enabled and impacted digitalization. Software development is a part of IS development, which is a part of digitalization business development. In our opinion, the framework of Figure 1 describes the connection of the three layers from the ISDM selection perspective. Software development should support ISD development rather than just develop software. In other words, it is necessary to consider the delivery and roll out, the operations, the maintenance, the service management, the user education, and the other IS development activities of the developed software already during software development. Similarly, IS development should support business (process) development, such as business process and change management, service design and business model crafting. We understand this to mean organized dialogue between software, IS and business development, preferably without hierarchical relations between the three. They all need both inputs and insights from the others. Future research, however, needs to verify this proposition.

Business development could - and probably should - be broken into smaller development streams, such as process development, marketing and sales planning, delivery channel and logistics planning and other relevant development streams, for example on the basis of business model and/or service design canvas dimensions. Software, IS and business development activities should also to be linked to (IT) service management activities in order to operate, maintain and further-develop the delivered outcomes of development. Furthermore, the use of software and IS (services) creates streaming and/or storable data that has value as such or as reused. An obvious conclusion is that the methods used in the development of software, IS and the various business development streams need to deliver outcomes, which are complementary and compatible. We reason that the selection and use of methods that fit to the characteristics of digitalization business development is one of the means to ensure that.

As discussed earlier, plan-driven ISDMs typically use such terms as systems design and systems engineering to describe ISD work. These ISDMs attempt to include business requirements with feasibility study and design phases, and address all IS development activities instead of only software development. Furthermore, plan-driven methods recognize the need to cover the entire life-cycle of an IS and the need to separately develop business (processes). For example, in the systems engineering waterfall ISD process model, the feasibility study, system deployment and system maintenance phases bring these issues inside of IS development. On the other hand, plan-driven ISDMs seldom offer advice on how to interact with business (process) development.

Although the agile manifesto [4] emphasizes the continuous need of interaction between software developers and business professionals, change-driven ISDMs focus on software development as if it was independent of the entire IS life-cycle and business (process) development contexts. Change-driven ISDMs offer limited guidance on how business requirements are discovered and validated. This work is left to so called product owners and to the dialogue between the product owner and the scrum manager. The assumption is that the product owner brings business needs in the form of ready-chewed pieces called user stories. User stories are collected into a product backlog (in Scrum) or into backlogs and epics (in SAFe / DevOps). The product owner and developers choose the most suitable pieces for the next development round (sprint) in a sprint planning meeting. The developers then develop the selected user stories into software code and typically compile the code into a new software version at the end of each sprint. This approach might be efficient in terms of software code development but excludes IS life cycle and business context issues.

We reason that the software focus of change-driven ISDMs may create challenges in such digitalization contexts where business (processes) should be remarkably changed and developed. We collected data from a third ISD project to a recent article [18] and witnessed this challenge. The software code for a permissioned private blockchain platform was developed with the SAFe method. The platform automates the exchange of supply chain and logistics documents between enterprises. SAFe was selected to develop software, since both blockchain technology and the automation of data exchange between enterprises had significant uncertainties. Business professionals and software developers agreed to work jointly also in the development of the various business processes needed to execute the platform-enabled business. The following challenge is descriptive from the perspective of the present article. According to the platform business model, customers download certificates, user identifications and the client programs of the platform from a data-center cloud without manual intervention. A lot of challenges and costs had been avoided if there had been an appropriate interactive communication mechanism. Software developers would probably have understood earlier that the business model requirement was to develop a simple automated service delivery solution together 
with the IS requirements to deliver the software from a cloud with necessary 365/24/7 data-center support services. Software developers could also have been able to propose earlier business strategy related software ideas that were later discussed separately.

\subsection{Research on the non-use of ISDMs}

In addition, ISDM selection, it is also necessary to use the selected methods. In the first section of the present article we disclosed the finding of extant literature that most ISD projects are executed without the proper use of any ISDM [21, 22, 26, 27, 35] for various reasons [7, 13, 22, 44]. For example, Fitzgerald [22] discovered that $60+\%$ of the organizations he studied (at the time) did not use any ISDM method, and $79 \%$ did not even intend to do so. Only $6 \%$ of organizations that he investigated used an ISDM rigorously [22]. Other studies have reported similar results [44]. Extant literature suggests several reasons for the ignorance of ISDMs. Fitzgerald [22] discovered that some IS developers are unwilling to use any ISDM. Cockburn [14] and Boehm and Turner [7] found out that some IS developers are unable to understand relevant methods. Even if they would be able to understand the methods, the values of an ISD team may determine, what ISDM is used [12]. Truex, Baskerville and Travis [44] detected that, in addition to IS developers, the same challenges of understandability and fit characterizes also ISDMs. The use of ISDMs in practice meets gnawing problems. ISDMS are discovered to suit poorly to some individuals, and they are considered unreliable in some settings [31, 44].

Marques et al. [35] studied reasons for the poor implementation of software development process. Poor communication and management problems, for example lack of time, were discovered to be major reasons. These reasons are external to ISD projects but obviously hamper opportunities to use selected ISDMs.

\section{Collection of empirical data}

We contacted IS development and project management experts to collect their opinions about the two research question of this article. In December 2018, we organized a workshop with 14 board and other active members of the Finnish software measurement association (FiSMA). In May 2020, we organized a similar workshop with 7 board and active members of the Project Management Association Finland (PMAF) the national chapter of International Project Management Association (IPMA). Due to COVID-19 the latter workshop was virtual.
In both workshops the chairman of the board for the respective association opened the workshop and presented us. We then gave a 30-minute presentation about our research on ISDM selection with the same set of 15 slides. After that we asked and displayed on a screen the question; According to your experience should IS development methods used in ISD projects fit to the characteristics of business development contexts, and if so or not so for what reasons? We gave workshop participants 30 minutes to write their answers into a Google docs document shared and visible to all participants, (which we ensured). Workshop participants saw in real-time answers written into the shared document and were allowed and encouraged to continue and comment but not change or remove other participants' answers. We then repeated the same for the question; According to extant research IS development methods are rarely used in earnest in IS development projects. Is this kind of behavior true according to your experience, and if so or not so for what reasons? A workshop ended with a discussion.

We selected this data collection method due to efficiency, interactive participative nature and anonymity reasons. During writing to the document, it was possible to see the writer identifications at the positions of their cursors but after that each answer and comment became anonymous. In group discussions, discussants may forget previous answers, have hearing problems and/or be dominated by some discussant(s) through their verbal and/or gestural behavior. Due to writing, participants also express their answers and comments with less meaningless words. The output is a complete document about the written discussion. We used Google docs since we could make it accessible to all participants for simultaneous writing without the need to first teach participants, how to use a groupwork IS or without prior registration to a workshop.

Similar to other group discussion data collection methods, the chosen method is vulnerable to the risk of "group thinking". Group thinking means that individual opinions disappear as individuals are willing to accept a group opinion even though they see the discrepancy to their own knowledge [28]. We selected the experienced members of FiSMA and PMAF to minimize this risk. There was another reason to recruit these groups. Although we did our best to make the two workshop questions neutral, they may still lead responses. Since we knew that the participants are eager to present their opinions, we explained that there is no right, optimal, preferred or desired answers. Both groups were informed in advance about the subject and nature of the workshop, and participation was entirely voluntary. On the other hand, we were looking for the synergy of experts. In other words, we hoped that the 
experts would add, challenge and develop further the opinions and ideas of each other.

In the analysis of the data we, indeed, detected synergy between expert opinion without group thinking. Responses were complemented and continued, which showed synergy. Insightful opposing comments indicated that experts dared to remain experts without slipping into group thinking.

\section{Findings and identified research areas}

\subsection{Answers to the workshop questions.}

In the first question of the workshops we requested workshop participants to respond to the question should ISDMs fit to the characteristics of the business development context. All responses favored the match bur saw it happen seldom. Below are representative quotes from the shared document - all translations from the local Finnish language to English are ours:

"My answer is yes ... it is quite difficult to imagine how the system would work if the business environment, its operation and development activities did not fit together" (FiSMA)

"Even if you develop a highly regulated function into the core of the bank's information systems, you are not as agile as a FinTech team. Thus, different parts of the same organization must have the ability to develop IS with different methods" (FiSMA)

"The business environment and its change management system (management system) need to be coordinated, but I see that development methods should be combined with them when needed." (PMAF)

Respondents described several reasons why ISDMs were not matched to business development contexts. Management practices, financing of IS development, belief in the existence of a universal method (belief that one method fits to all needs) and the influence of objectives that are irrelevant to an ISD project were given as responses. Some representative quotes are:

"I've seen projects that entered production phase so that bonuses could be claimed, even though that application had no prospective customers ..." (FiSMA)

"The connection from development methods to a company's business is by no means straightforward irrespective of the source of the development, which could reflect the ideas of general management or the needs of business practice" (FiSMA)

"The risk-bearing capacity of the financing model is also much related to how purchase decisions are made (fixed-price projects)" (PMAF)

"Yes ... I have often seen that being agile is the objective benefits management put aside" (PMAF)

Some ISD experts (FiSMA) had opinions about factors that affect development method selection:
"The choice of methods must also be influenced by the maturity of the information system to be developed, i.e. what are the most important drivers of development. Version 1 could be a pure "time-tomarket" solution, version 2 could mean the creation of various new technical / business features, and (the development) version 3 could be driven by absolute quality, i.e. cost-of-failure." (FiSMA)

"Should projects that increase business (i.e. generate new revenue) be managed in a different way than projects that generate cost savings? How does this relate to the repayment of a technical debt (in agile methods)?" (FiSMA, words in brackets added by us to increase the readability of the quotation)

The second question of the workshops requested the respondents to contemplate possible reasons for not deploying ISDMs, should they agree with that finding of extant literature. The responses of ISD experts (FiSMA) and project management experts (PMAF) differed. ISD experts agreed to some extent with the finding whereas project management experts contested the finding. Here are representative quotes:

"The (ISDM) methods are not good enough for the developer team to buy them and actually adopt them." (FiSMA)

"In an information system project, the estimated benefits of the product are central. (What is) the development method is mainly a side issue." (FiSMA)

"Yeah, and the design and execution of the development work itself is seen only as a matter relevant for IT professionals" (FiSMA)

"Lack of competence - not enough attention has been paid to methods in universities of applied sciences and in science university education" (FiSMA)

"I have never been in any projects, where no method would have been deployed." (PMAF)

"I haven't come across this in my 35-year project management career." (PMAF)

"Agree with the previous comments, some kind of method has always been used." (PMAF)

The names of ISDMs and their evolution were addressed in many responses:

"If the "official" method is tailored to be unique (to an enterprise), it is probably no longer called with (the method's) original name. That is, the method has become a hybrid" (FiSMA)

"On the other hand, does anyone use a completely pure waterfall model anymore?" (FiSMA)

"Some method is always used, or there is at least an established way of doing it (=ISD work), even if it (=the method) would not have a name." (FiSMA)

"Many practical methods are some kind of hybrids. That is, if that (=the research finding) means this then there are no pure methods in use, and then I can partially agree with this finding." (PMAF) 


\subsection{Potential areas of future research}

On the basis of the argumentation presented in the Introduction and Related research sections and on the basis of the findings presented above we propose potential areas of future ISDM selection research. In our opinion, the following six are the most potential and welcome other researchers' propositions:

1. The role and significance of IS and software development in digitalization: We expressed that in our opinion IS and software development characterize and are fundamental to digitalization. Still, research-based evidence is insufficient to communicate their role concretely to managers and experts in business and IT.

2. Relations and coordination between software development, IS development and business development in digitalization context: Significant part of the related research section (2.1) addresses this issue. We have so far investigated this issue from the perspective, how ISDM should selected so that they fit to the characteristics of business (process) development. This could be turned around to investigate how business development methods such as business models and service design fit to ISDMs

3. Development of ISDM selection models and recommendations applicable to digitalization development contexts: We detected that the recommendations of extant literature are outdated and should be upgraded to address the current challenges of ISDM selection. Our ISDM selection framework needs additional evidence for validation including its possible replacement with more descriptive models.

4. Behavioral issues of ISDM selection and use: Finding reasons for and means to end the functionally stupid behavior of not understanding the significance of ISDM selections and not using selected ISDMs properly. This has the potential to improve the success rate of ISD projects and digitalization.

5. Relations between ISD and data management methods: The annual growth rate of digital data is $100 \%$ or more [19]. The use and/or reuse of digital data is often an important element of applications and ISs developed in digitalization development contexts. We need to understand how to link ISDMs and data management models, e.g. those covered in the DAMA Data Management Book of Knowledge (DMBOK).

6. Guidelines to select and compare methods in order to select one: There are several ISDMs and even more variants. Providing research-based advice to the selection of a suitable ISDM for a project is probably the most valuable research area to practitioners.

\section{Discussion and conclusions}

We organized two workshops with IS development and project management experts to find out their opinions about the underlying idea of our research. Our idea is that the characteristics of selected and used ISDMs should match with the characteristics of business development contexts. We asked the experts to write individually and simultaneously their opinions in favour or against such match into a shared document. The respondents were able to see in realtime the opinions of other respondents, could complement, comment or oppose them, but could not change or remove other experts' opinions. Participating experts strongly favoured the match but also expressed that they have seen such matches seldom in reality.

Ignorance regarding ISDM selection decisions' impacts on business and ISD project success, existing ISD project practices such as project funding practices, and lack of managerial skills were mentioned as the reasons for not considering the fit of ISDMs to the properties of development contexts. These two paragraphs are our answer to the first research question

Our ISDM selection framework advocates that method selection should be carried out at the project level. Although we had no question about this issue, several responses pointed out that the ISDM should be selected by considering project characteristics. For example, the participating ISD experts (FiSMA) suggested that "time-to-market" driven development need different approach than "cost-of-failure" driven development. Differences were also seen between fixed-priced, target-priced and time-and-materialspriced ISD projects. In our opinion, we received strong support to our proposition to upgrade and augment extant ISDM knowledge base by investigating the selection and use of ISDM (software and IS) and business (process) development methods in digitalization contexts.

In the same workshops we asked the same experts to ponder how earnestly ISDMs are used in ISD projects. Expert opinions varied a lot. Majority of participating ISD experts expressed that ISDMs are seldom deployed earnestly. On the other hand, the majority of participating project management experts had the opinion that ISDM are used earnestly. All respondents expressed that they had never met pure amethodical ISDM behaviour, that is all ISD projects had used ISDM methods at least to some extent. This finding differs from what has been reported in extant literature several times over the years [22, 27, 37].

IS developers' perceptions that ISDMs offer little value to them and that ISD project deliverables are all that counts irrespective of methods used were expressed as the reasons for not to use ISDMs. Educational and knowledge deficiencies were also mentioned with desire that both the universities of 
applied sciences and science universities would provide more and better quality ISD and ISDM education. These two chapters constitute our response to the second research question.

The above-mentioned interviews of 31 ISD and ISDM experts also provided mixed results. Four interviewees working on the borderline between IS user organizations and ISD service providers considered the amethodical approach as the prevailing practice, amethodical approach was rather common according to seven other interviewees, whereas the remaining 20 interviewees did not address this issue at all. Differences in understanding, what earnest deployment of ISDMs mean, is one obvious reason for mixed results. We did not define earnest deployment of ISDMs in order not to lead the answers of respondents. Some may understand earnest deployment to mean the following of guidelines by the book, for example as advised in an ISDM manual. Others may think that methods should not be like fetishes carved into stone, rather they should be applied in a context [27]. Some of the studies that have discovered that amethodical practices are common are rather old, for example [37] and [22]. It is possible that similarly to the models and recommendations of ISDM selection the situation may have changed. Our interviews and workshops have been conducted two or three decades later and that may explain, why detected only small amounts of amethodidical ISDM behaviour. Finally, it is possible that due to possible fears of negative consequences, IS and software developers explain that they use ISDMs when they in fact do not, see e.g. [2]. Our conclusion is that this issue deserves additional research and attention. We see that already happening [20].

In the present article, we proposed in section $4.2 \mathrm{six}$ potential areas of future research. In addition to the identified research areas also to topics discussed in this section are amenable for future studies. The present article contributes to research with the answers to the two research questions, with the proposals of six research areas and by describing the journey behind the ISDM selection framework presented in this article and in our prior studies, such as [32].

Similar to any study our article has limitations, some of which are at the same time opportunities for future research. The data was collected only from one Northern European Union (EU) country. We hope that we will be able to collect data from other EU and EEA countries in the planned research efforts. Data from more workshops would increase the reliability of our empirical findings and feedback from other researchers would strengthen our future research related proposals.

Our advice to researchers is to consider and to investigate the relations between software, IS and business development, and especially to consider this in various digitalization contexts. Our advice to practitioners is to select and use ISDMs by considering the relevance and fit of the selected ISDM to the development task. We also encourage practitioners to understand the ISDMs they deploy.

\section{References}

[1] Ahimbisibwe, A., R.Y. Cavana, and U. Daellenbach, “A contingency fit model of critical success factors for software development projects A comparison of agile and traditional plan-based methodologies", Journal of Enterprise Information Management 28(1), 2015, pp. 7-33.

[2] Argyris, C., "Organizational Learning and Management Information Systems", Accounting, Organizations and Society 2(2), 1977, pp. 113-123.

[3] Barney, J., "Firm resources and sustained competitive advantage", Journal of management 17(1), 1991, pp. 99-120. [4] Beck, K., M. Beedle, A. van Bennekum, et al., "Manifesto for Agile Software Development", 2001.

[5] Behutiye, W.N., P. Rodríguez, M. Oivo, and A. Tosun, "Analyzing the concept of technical debt in the context of agile software development: A systematic literature review", Information and Software Technology 82, 2017, pp. 139158.

[6] Benington, H.D., "Production of Large Computer Programs", Annals of the History of Computing 5(4), 1983, pp. 350-361.

[7] Boehm, B.W., and R. Turner, Balancing agility and discipline: A guide for the perplexed, Addison-Wesley Professional, 2004.

[8] Borg, M., J. Wernberg, T. Olsson, U. Franke, and M. Andersson, "Illuminating a Blind Spot in Digitalization Software Development in Sweden's Private and Public Sector", IEEE/ACM 42nd International Conference on Software Engineering Workshops (ICSEW'20), (2020). [9] Brooks, F.P.J., "No silver bullet - essence and accidents of software engineering", Proceedings of the IFIP Tenth World Computing Conference, (1986), 1069-1076.

[10] Burns, R.N., and A.R. Dennis, "Selecting the appropriate application development methodology", ACM Sigmis Database(613), 1985.

[11] Bylund, P.L., "Signifying Williamson's Contribution to the Transaction Cost Approach: An Agent-Based Simulation of Coasean Transaction Costs and Specialization", Journal of Management Studies 52(1), 2015, pp. 148-174.

[12] Cockburn, A., "Selecting a project's methodology", IEEE Software 17(4), 2000, pp. 64-71.

[13] Cockburn, A., Crystal Clear: A Human-Powered Methodology for Small Teams: A Human-Powered Methodology for Small Teams, 2004.

[14] Cockburn, A., Agile Software Development, Pearson education, Crawfordsville, Indiana, 2007.

[15] Dahlberg, T., and H. Kivijarvi, "Towards an Integrative, Multilevel Theory for Managing the Direct and Indirect Impacts of IT Project Success Factors", Proceedings of the Annual Hawaii International Conference on System Sciences, IEEE Computer Society (2016), 4971-4980.

[16] Dahlberg, T., and A. Lagstedt, "There Is Still No ' Fit for All' IS Development Method : Business Development 
Context and IS Development Characteristics Need to Match", Proceedings of the 51st Hawaii International Conference on System Sciences, (2018).

[17] Dahlberg, T., and A. Lagstedt, "The Usefulness of the Recommendations Regarding the Information System Development Method Selection during the Era of Digitalization", Proceedings of the 52nd Hawaii International Conference on System Sciences 2019, (2019). [18] Dahlberg, T., and A. Lagstedt, "On Solving the Business Requirements Engineering Problems of Information Systems Development Projects - Lessons from Three Projects", Proceedings of the 53rd Hawaii International Conference on System Sciences, (2020).

[19] Dahlberg, T., A. Lagstedt, and T. Nokkala, "How to address master data complexity in information systems development - A federative approach", 26th European Conference on Information Systems: Beyond Digitization Facets of Socio-Technical Change, ECIS 2018, (2018). [20] Dittrich, Y., "What does it mean to use a method? Towards a practice theory for software engineering", Information and Software Technology 70, 2016, pp. 220231.

[21] Dolezel, M., A. Buchalcevova, and M. Mencik, "The State of Agile Software Development in the Czech Republic: Preliminary Findings Indicate the Dominance of 'Abridged' Scrum”, In P. Doucek, J. Basl, A. Tjoa, M. Raffai, A. Pavlicek and K. Detter, eds., Research and Practical Issues of Enterprise Information Systems. CONFENIS 2019. Lecture Notes in Business Information Processing, vol 375. Springer, Cham, 2019, 43-54.

[22] Fitzgerald, B., "An empirical investigation into the adoption of systems development methodologies", Information \& Management 34(6), 1998, pp. 317-328. [23] Hanssen, G.K., and T.E. Fægri, "Agile customer engagement: A longitudinal qualitative case study", ISESE'06 - Proceedings of the 5th ACM-IEEE International Symposium on Empirical Software Engineering, (2006), 164 173.

[24] Holvitie, J., S.A. Licorish, R.O. Spínola, et al., "Technical debt and agile software development practices and processes: An industry practitioner survey", Information and Software Technology 96(November 2017), 2018, pp. 141-160.

[25] Howell, D., C. Windahl, and R. Seidel, “A project contingency framework based on uncertainty and its consequences", International Journal of Project Management 28(3), 2010, pp. 256-264.

[26] Huisman, M., and J. Iivari, "Deployment of systems development methodologies: Perceptual congruence between IS managers and systems developers", Information and Management 43(1), 2006, pp. 29-49.

[27] Iivari, J., and M. Huisman, "The Relationship between Organizational Culture and the Deployment of Systems Development Methodologies", MIS Quarterly 31(1), 2007, pp. 35-58.

[28] Janis, I.L., “GroupThink”, Psychology today 5(6), 1971, pp. 43-46.

[29] Kivijärvi, H., "Theorizing IT project success: Direct and indirect effects in a hierarchical framework", International Journal of Information Technology Project Management, 2020.
[30] Krogh, G. Von, C. Rossi-Lamastra, and S. Haefliger, "Phenomenon-based research in management and organisation science: When is it rigorous and does it matter?", Long range planning 45(4), 2012, pp. 277-298. [31] Lagstedt, A., "Selecting the Right Method for the Right Project", 2019.

[32] Lagstedt, A., and T. Dahlberg, “A Contingency Theory Motivated Framework to Select Information System Development Methods", Pacific Asia Conference on Information Systems, (2018), 1-14.

[33] Lenberg, P., R. Feldt, and L.G. Wallgren Tengberg, "Misaligned values in software engineering organizations", Journal of Software: Evolution and Process 31(3), 2019, pp. $1-21$.

[34] Mahmood, M. a., "System development methods - A comparative investigation", MIS Quarterly: Management Information Systems 11(3), 1987, pp. 293-307. [35] Marques, R., G. Costa, M. Mira da Silva, and P. Gonçalves, "A survey of failures in the software development process", Proceedings of the 25th European Conference on Information Systems, ECIS 2017, (2017), 2445-2459.

[36] Nelson, R.R., "Project retrospectives: Evaluating project success, failure, and everything in between [Electronic version]", MIS Quarterly Executive, 2005.

[37] Parnas, D.L., and P.C. Clements, "A Rational Design Process: How and Why to Fake It", IEEE Transactions on Software Engineering SE-12(2), 1986, pp. 251-257.

[38] Pinto, J.K., and D.P. Slevin, "Project Success : Definitions and Measurement Techniques", Project Management Journal, 1988.

[39] Pinto, J.K., and D.P. Slevin, "Critical success factors across the project life cycle", Project Management Journal, 1988.

[40] Standish Group, CHAOS Report 2015, 2015.

[41] Theocharis, G., M. Kuhrmann, J. Münch, and P.

Diebold, "Is water-scrum-fall reality? On the use of agile and traditional development practices", International Conference on Product-Focused Software Process Improvement, Springer (2015), 149-166.

[42] Thompson, J.D., Organizations in Action: Social Science Bases of Administrative Theory, Transaction Publishers, 2003.

[43] Thummadi, B.V., O. Shiv, N. Berente, and K. Lyytinen, "Enacted software development routines based on waterfall and agile software methods: Socio-technical event sequence study", Lecture Notes in Computer Science (including subseries Lecture Notes in Artificial Intelligence and Lecture Notes in Bioinformatics) 6629 LNCS, 2011, pp. 207-222.

[44] Truex, D., R. Baskerville, and J. Travis, "A methodical Systems Development: The Deferred Meaning of Systems Development Methods", Accounting, Management and Information Technology 10, 2000, pp. 53-79.

[45] Welch, C., R. Piekkari, E. Plakoyiannaki, and E. Paavilainen-Mäntymäki, "Theorising from case studies: Towards a pluralist future for international business research", Journal of International Business Studies 42, 2011, pp. 740

[46] "Gartner Market Databook, 2Q12 Update", https://www.gartner.com.doc/20703316/gartner-marketdataook-q-update, 2012. 